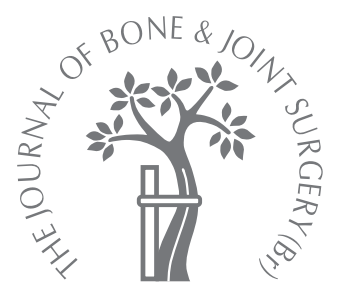

G. P. Grobler, I. D. Learmonth, B. P. Bernstein, B. J. Dower

From the Princess Alice Orthopaedic Unit, Groote Schuur Hospital, Cape Town, South Africa

- G. P. Grobler, MBChB(UCT), FRCS(Ed), FCS(SA) Orth, Mmed(UCT), Orthopaedic Surgeon, Senior Consultant B. P. Bernstein,

MBChB(Wits), FCS(SA) Orth, Orthopaedic Surgeon

B. J. Dower, MBChB, FCS Orth(SA), De Puy Arthroplasty Fellow and Consultant

Suite 1001, Vincent Pallotti Hospital, Alexandra Road, Pinelands 7405, South Africa.

I. D. Learmonth, MBChB, FRCS(Eng), FRCS(Ed), FCS(SA) Orth, Professor of Orthopaedic Surgery Department of Orthopaedic Surgery

Level 5, Bristol Royal Infirmary, Bristol BS2 8HW, UK.

Correspondence should be sent to Dr. G. P. Grobler at P. O. Box 53503, Kenilworth 7745, South Africa; e-mail: garth.grobler@ vincentpallotti.com

(C2005 British Editorial

Society of Bone and

Joint Surgery

doi:10.1302/0301-620X.87B6. $15335 \$ 2.00$

$J$ Bone Joint Surg [Br] 2005;87-B:786-9.

Received 26 January 2004; Accepted after revision 8 September 2004

\title{
Ten-year results of a press-fit, porous-coated acetabular component
}

\author{
We retrospectively reviewed, ten years after surgery, 100 consecutive total hip \\ replacements in which the Duraloc 300 cup had been used. Post-operative radiographs \\ were analysed for placement of the cup and interface gaps and follow-up radiographs for \\ lucent lines, osteolysis, wear and migration. \\ All the components were found to be stable with no evidence of loosening. The mean \\ rate of wear was $0.12 \mathrm{~mm} /$ year. Three hips developed acetabular osteolysis at the level of \\ the apex hole. Two have successfully undergone bone grafting without removal of the \\ implants and one patient is awaiting surgery. The Duraloc 300 cup has a survival of $100 \%$ at \\ ten years with no aseptic loosening and a low incidence of pelvic osteolysis.
}

First-generation cementless prostheses had a number of design flaws which have now been addressed. These included thin polyethylene, a poor locking mechanism and sharp edges to the screw holes. These features resulted in the generation of polyethylene debris from both the bearing surface and from so-called backside wear. ${ }^{1-3}$ The Duraloc 300 (DePuy, Warsaw, Indiana) is a three-pegged, less than hemispherical, porous-coated, titanium acetabular component (Fig. 1). A ring-locking mechanism secures the polyethylene liner. The geometry of the shell and dome of the liner is precisely spherical and ensures efficient load transfer and low contact stresses. The component's Porocoat surface (DePuy) has a mean pore size of $250 \mu \mathrm{m},{ }^{4}$ and three stabilising pegs offer additional rotational security. We used a polyethylene liner with a lip of $10^{\circ}$. The polyethylene was sterilised by gamma irradiation in air.

Our results at five years had been promising, with no case of aseptic loosening. We have now evaluated our results at ten years in order to establish whether the continued increasing use of this component was justified.

\section{Patients and Methods}

Between August 1991 and July 1993, we performed 100 consecutive total hip replacements (THRs) in 93 patients (48 men and 45 women). Two men and five women underwent a bilateral procedure. Their mean age at operation was 54 years (24 to 71 ). The diagnosis was osteoarthritis in 60 hips, avascular necro- sis in ten, rheumatoid arthritis in ten, dysplasia in nine, post-traumatic arthritis in three, Gaucher's disease in one, arthrodesis in one, and other diagnoses in six. Two experienced hip surgeons performed 93 operations and seven were undertaken by registrars under supervision.

An anterior, partial trochanteric osteotomy approach was used with the patient in a lateral decubitus position. ${ }^{5}$ The anterior capsule was excised and osteophytes resected. The acetabulum was under-reamed by the thickness of the Porocoat and the cup impacted at an abduction angle of $45^{\circ}$, with anteversion corresponding to that of the patient's acetabulum.

The Duraloc system has a range of acetabular implants, including a shell which can be augmented by screws if a firm press-fit is not achieved. These were not required in our patients. The eliminator screw was not available in this series. The polyethylene liner was inserted with its long $10^{\circ}$ lip in the best position after a trial reduction. A stainless-steel head was used for all hips.

Of the 93 patients, 22 (23 hips) died at a mean of six years after surgery. None had undergone revision and all had a satisfactory fixation of the implant as seen on radiographs taken at a mean of 1.3 years before death. Four patients (four hips) could not be traced, leaving 67 patients (73 hips) available for analysis. All had been followed for more than ten years.

Radiological examination was made on anteroposterior radiographs of the pelvis taken soon after surgery, at five years and final fol- 


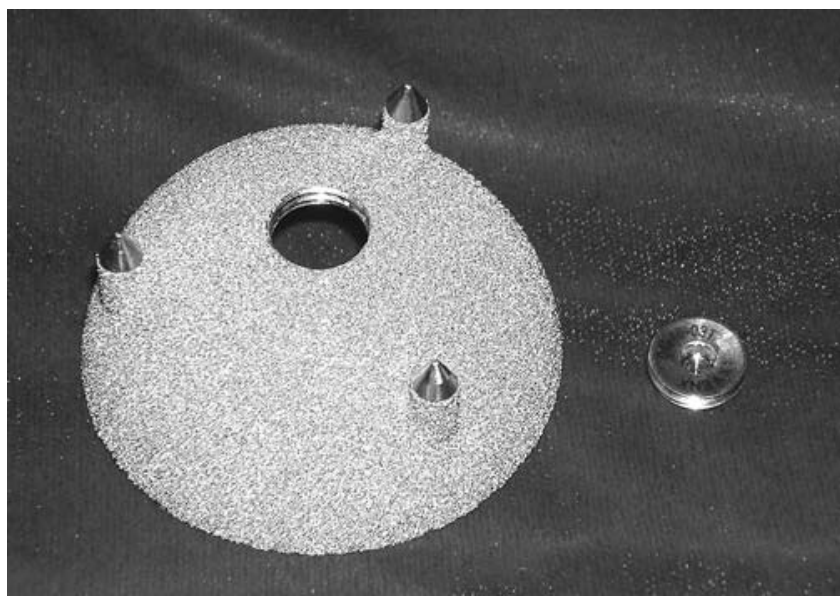

Fig. 1

Photograph of the Duraloc 300 implant showing its three-pegged titanium shell and Porocoat surface. We did not use the eliminator screw in this series.

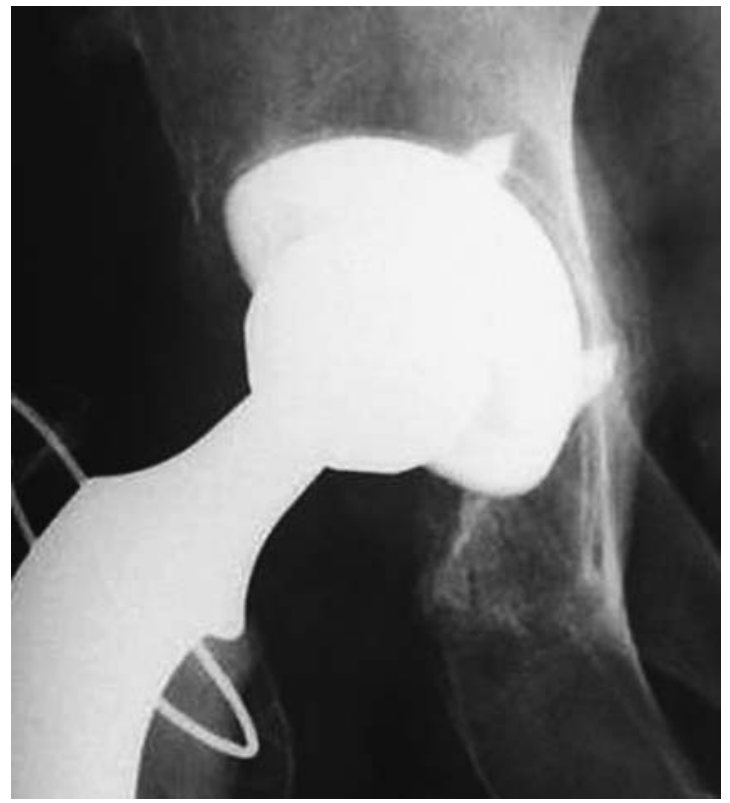

Fig. 2

Radiograph of a well-fixed Duraloc cup at ten years.

low-up. Migration, lucent lines, the abduction angle, osteolysis and wear of polyethylene were assessed. All measurements were made by a single observer (BJD) who had not participated in the surgery. Radiolucent lines were evaluated in the three zones described by DeLee and Charnley. ${ }^{6}$ Osteolysis was defined as a circular or oval area of distinct bone loss. Evidence of migration was measured on the follow-up radiographs. The acetabular component was considered loose if there was $\geq 3 \mathrm{~mm}$ of migration from either the inter-tear-drop or vertical lines, or a change of $\geq 4^{\circ}$ in

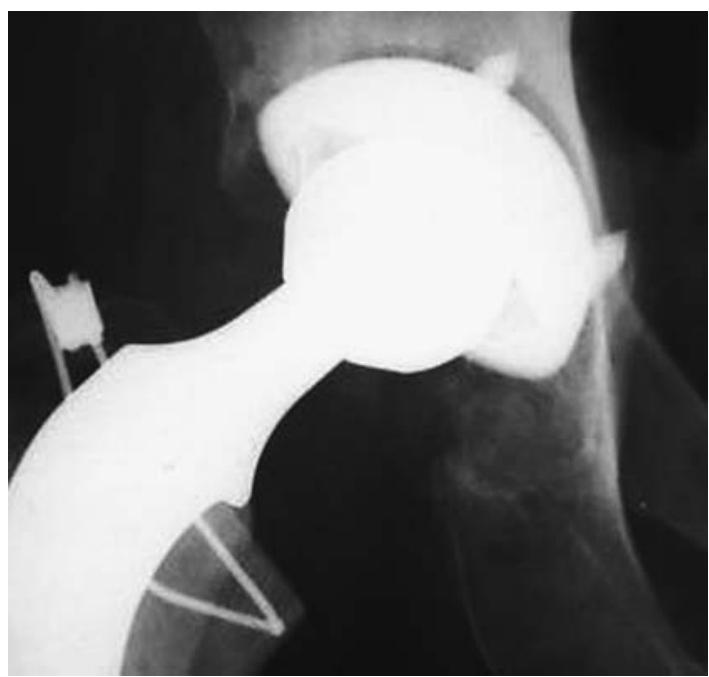

Fig. 3a

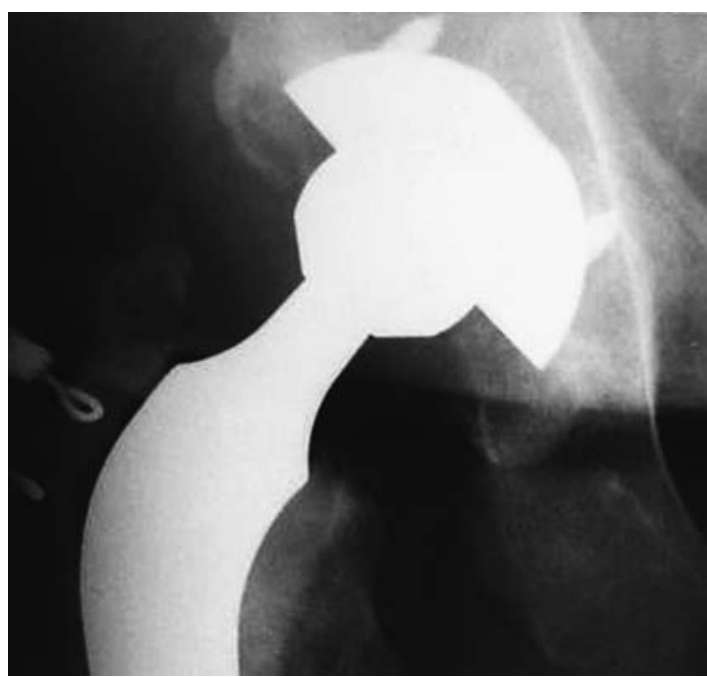

Fig. 3b

Radiographs taken a) immediately after operation showing a lucency in zone 2 where the prosthesis was not perfectly seated and b) at ten years showing a stable prosthesis and new bone formation at the interface.

the abduction angle. ${ }^{7}$ Linear polyethylene wear was measured using a digital hip analysis suite. ${ }^{8,9}$ Five measurements were taken for each patient and a mean value was calculated. The analysis was performed on digitised radiographs. The underlying approach of the computer-assisted vector analysis of wear was to find the circles which best fitted the prosthetic femoral head and the acetabular component. The magnitude and direction of the displacement of the femoral head vector from the acetabular centre were calculated on follow-up radiographs at ten years. If the polyethylene liner required exchange, measurements were made on the radiograph taken immediately before this revision. 


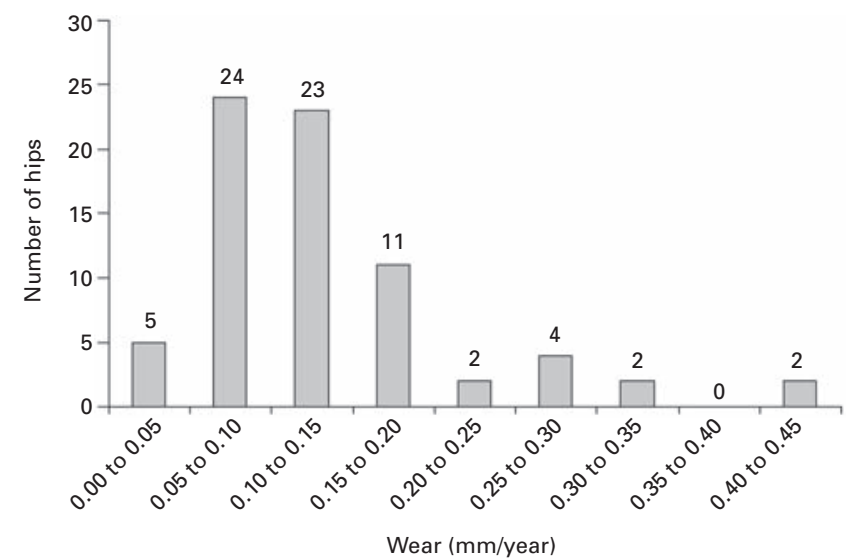

Fig. 4

Bar chart showing the degree of wear in the 73 hips.

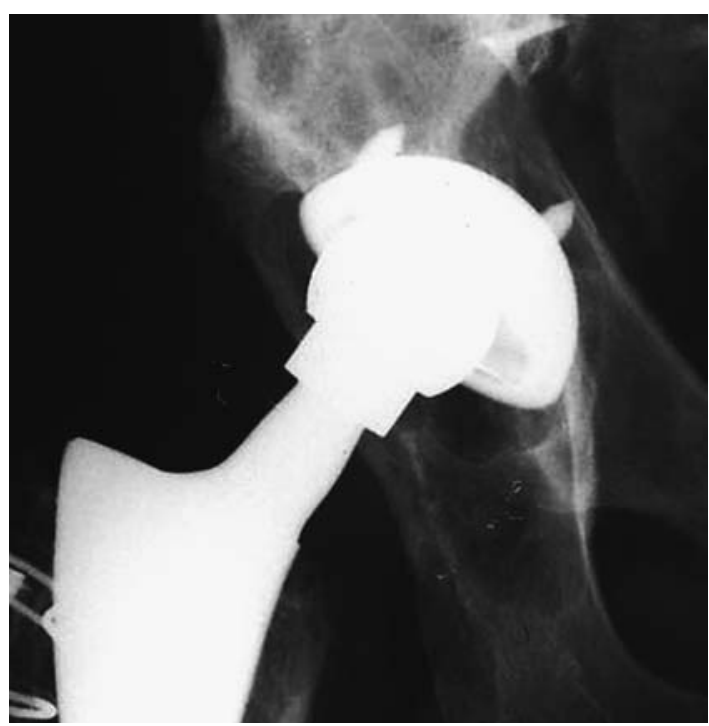

Fig. $5 a$

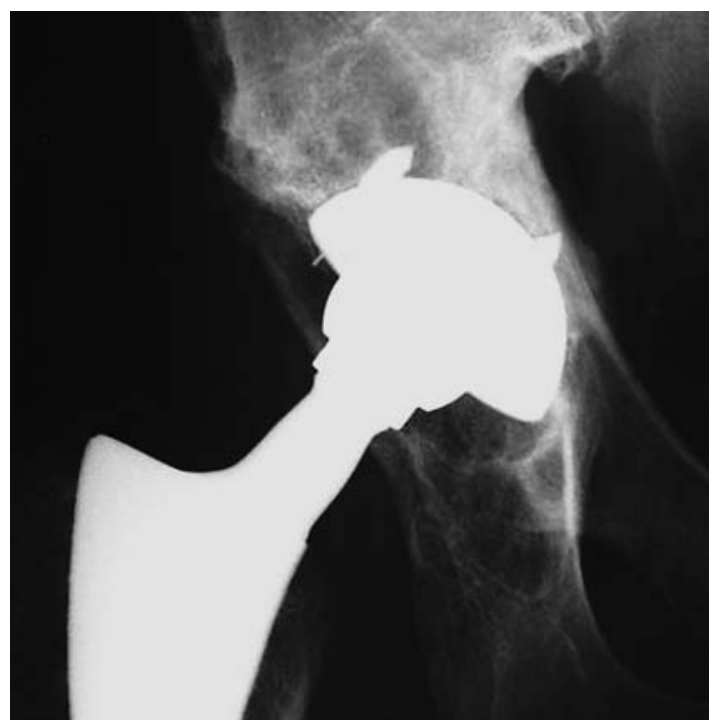

Fig. $5 \mathrm{c}$

\section{Results}

Radiological analysis. At ten years, 64 hips showed a wellfixed acetabular component with no radiolucencies (Fig. 2). Twenty-seven had a lucency around the component on the initial post-operative radiograph. Of these, 12 had a lucency in two zones, one a lucency in three and 14 a lucency in one. Only nine hips still had a lucency around the component on the radiographs taken at five years. At ten years after surgery, none of the lucencies seen at five years had progressed and no new lucencies had appeared (Fig. 3). No lucency seen at ten years was more than $1 \mathrm{~mm}$ wide and no acetabular component showed evidence of migration. The mean rate of linear wear was $0.12 \mathrm{~mm} /$ year (Fig. 4). In the three patients who developed granulomata, the wear was $0.17,0.20$ and $0.43 \mathrm{~mm} /$ year, respectively. The mean angle of abduction was $43^{\circ}$ (30 to 60 ). There was

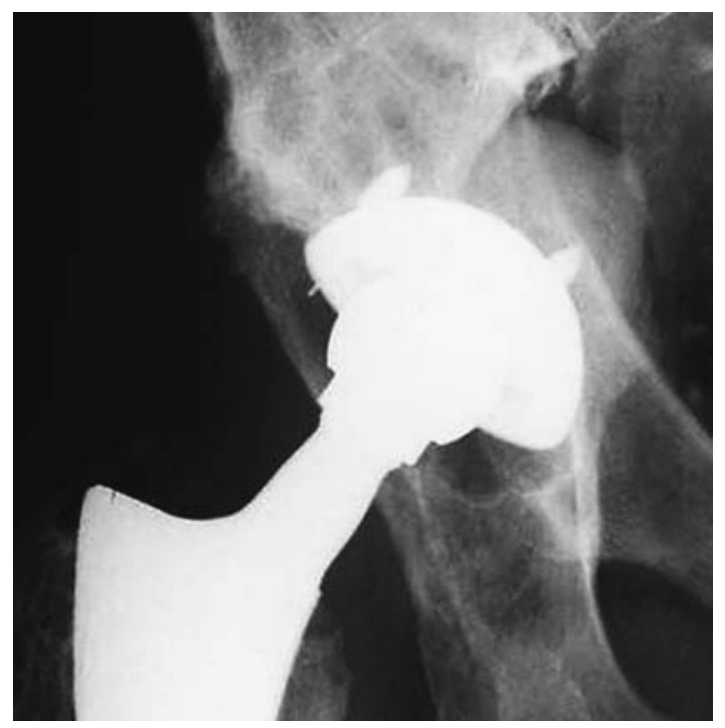

Fig. $5 b$

Radiographs showing a) a large periacetabular granuloma with polyethylene wear at six years, b) bone graft inserted through the central hole and c) regeneration of bone and remodelling five years after revision. 
no correlation between wear and abduction, thickness of the polyethylene, the age of the patient or pre-operative diagnosis.

Survival of the component. No acetabular component was revised for aseptic loosening. One patient had a dislocation two months after surgery; the liner was revised with adjustment of its long wall and the patient had a successful outcome. Three patients developed peri-acetabular osteolysis. In two, bone grafts were inserted through the central hole in the cup and the liners were renewed at the same time. In both patients the bone graft incorporated and no further lysis was seen (Fig. 5). One patient is awaiting a similar bone-grafting procedure; one patient underwent routine revision of the liner at the time of revision of the stem and two had revision of a well-fixed acetabular component at the time of their femoral revision. These three procedures were performed at another institution.

Statistical analysis. Kaplan-Meier survivorship analysis was performed, taking loosening and revision of the liner as an end-point. The rate of survival at ten years for loosening was $100 \%$ and for revision of the liner $95.39 \%$ (95\% confidence interval 94.86 to 95.92 ).

\section{Discussion}

Our study has shown that a porous, cementless, threepegged cup (Duraloc 300 series) inserted with a press-fit technique, provides satisfactory results. No cups were revised for loosening and none showed radiological signs of loosening. ${ }^{10-12}$ Stockl et al ${ }^{13}$ used the Ein Bild Röentgen Analysis (EBRA) method to measure the migration of 71 primary THRs using the Duraloc 100 series which has no pegs but achieves press-fit fixation. They noted that EBRA had an accuracy of $1 \mathrm{~mm}$ but paradoxically defined loosening as a total migration of $1 \mathrm{~mm}$. By their definition $48 \%$ of their cups were loose at 24 months. Their predictions were not supported by the findings of either Kim, Oh and $\mathrm{Kim}^{14}$ or Young et $\mathrm{al}^{15}$ who together reviewed 100 THRs using a Duraloc 100 cup. The mean follow-up was 6.3 years and 5.5 years, respectively. There was no loosening of the cup. Many would suggest that migration of $2 \mathrm{~mm}$ or more is discernible on standard radiographs. However, because of the lack of standardisation of our radiographs, we have used a minimum of $3 \mathrm{~mm}$ to define migration. Although our results are encouraging, only further follow-up will determine whether durable long-term fixation can be achieved.

A rate of $0.12 \mathrm{~mm} /$ year is similar to that seen in other studies. ${ }^{16,17}$ There was no correlation between abduction, age, thickness of the polyethylene, diagnosis and wear. We suspect that other factors, such as the quality, manufacturing and shelf life of the polyethylene may be implicated in those cases showing excessive polyethylene wear. We assume that the bearing surface can easily be changed to any combination of materials with better wear properties and without altering the results of fixation of the cup. Although we still use liners with lips when required in order to achieve stability, we do not recommend the use of skirted metal heads, which can cause impingement. Cementless fixation provides dynamic, biological security, which is continuously renewed over time. It may be expected that the durability of fixation will extend well beyond ten years, although rates of wear will need careful monitoring. The major challenge facing today's arthroplasty surgeons remains wear at the bearing surface.

One or more of the authors have received or will receive benefits for personal or professional use from a commercial party related directly or indirectly to the subject of this article. In addition, benefits have been or will be directed to a research fund, foundation, educational institution, or other nonprofit organisation with which one or more of the authors are associated.

\section{References}

1. Barrack R, Burke D, Cook S, Skinner H, Harris W. Complications related to modularity of total hip components. J Bone Joint Surg [Br] 1993;75-B:688-92.

2. Brien W, Salvati E, Wright T, et al. Dissociation of acetabular components after hip arthroplasty. J Bone Joint Surg [Am] 1990;72-A:1548-50.

3. Lallaghan J, Kim Y, Brown T, Pederson D, Johnston R. Concerns and improvements with cementless metal-backed acetabular components. Clin Orthop 1995;311 76-84.

4. Bobyn JD, Pilliar RM, Cameron HU, Weatherly GC. The optimum pore size for the fixation of porous-surfaced metal implants by the ingrowth of bone. Clin Orthop 1980; 150:263-70.

5. Dall DM, Miles AW. Re-attachment of the greater trochanter: the use of the trochanter cable-grip system. J Bone Joint Surg [Br] 1983;65-B:55-9.

6. DeLee JG, Charnley J. Radiological demarcation of cemented sockets in total hip replacements. Clin Orthop 1976;121:20-32.

7. Massin P, Schmidt L, Engh CA. Evaluation of cementless acetabular component migration: an experimental study. J Arthroplasty 1989;4:245-51.

8. Hui A, McCalden R, Martell J, et al. Validation of two and three-dimensional radiographic techniques for measuring polyethylene wear after total hip arthroplasty. J Bone Joint Surg [Am] 2003;85-A:505-11.

9. Martell J, Berdia S. Determination of polyethylene wear in total hip replacements with use of digital radiographs. J Bone Joint Surg [Am] 1997;79-A:1635-41.

10. Sychterz C, Claus A, Engh C. What we have learned about long-term cementless fixation from autopsy retrievals. Clin Orthop 2002;405:79-91.

11. Pollock D, Sychertz C, Engh C. A clinically practical method of manually assessing polyethylene liner thickness. J Bone Joint Surg [Am]2001;83-A:1803-10.

12. Wright J, Pellicci $P$, Salvati $\mathbf{E}$, et al. Bone density adjacent to press-fit acetabular components. J Bone Joint Surg [Am] 2001;83-A:529-36.

13. StockI B, Sandow M, Krismer M, et al. Migration of the Duraloc cup at two years J Bone Joint Surg [Br] 1999;81-B:51-3.

14. Kim YH, Oh SH, Kim JS. Primary total hip arthroplasty with a second-generation cementless total hip prosthesis in patients younger than fifty years of age. J Bone Joint Surg [Am] 2003;85-A:109-14.

15. Young AM, Sychterz CJ, Hopper RH Jr, Engh CA. Effect of acetabular modularity on polyethylene wear and osteolysis in total hip arthroplasty. J Bone Joint Surg [Am] 2002;84-A:58-63.

16. Udomkiat P, Dorr L, Wan Z. Cementless hemispheric porous sockets implanted with press-fit technique without screws: average ten-year follow-up. J Bone Joint Surg $[$ Am] 2002;84-A:1195-200.

17. Clohisy JC, Harris WH. The Harris-Galante porous coated acetabular component with screw fixation: an average ten-year follow-up study. J Bone Joint Surg [Am] 1999;81-A:66-73. 